\title{
Drug abuse in athletes
}

This article was published in the following Dove Press journal:

Substance Abuse and Rehabilitation

14 August 2014

Number of times this article has been viewed

\section{Claudia L Reardon \\ Shane Creado}

Department of Psychiatry, University of Wisconsin School of Medicine and Public Health, Madison, WI, USA
Correspondence: Claudia L Reardon University of Wisconsin School of Medicine and Public Health, Department of Psychiatry, 600I Research Park Boulevard, Madison, WI 537I9, USA

$\mathrm{Tel}+\mathrm{I} 6082636100$

Fax + I 6082629246

Email clreardon@wisc.edu
Abstract: Drug abuse occurs in all sports and at most levels of competition. Athletic life may lead to drug abuse for a number of reasons, including for performance enhancement, to selftreat otherwise untreated mental illness, and to deal with stressors, such as pressure to perform, injuries, physical pain, and retirement from sport. This review examines the history of doping in athletes, the effects of different classes of substances used for doping, side effects of doping, the role of anti-doping organizations, and treatment of affected athletes. Doping goes back to ancient times, prior to the development of organized sports. Performance-enhancing drugs have continued to evolve, with "advances" in doping strategies driven by improved drug testing detection methods and advances in scientific research that can lead to the discovery and use of substances that may later be banned. Many sports organizations have come to ban the use of performance-enhancing drugs and have very strict consequences for people caught using them. There is variable evidence for the performance-enhancing effects and side effects of the various substances that are used for doping. Drug abuse in athletes should be addressed with preventive measures, education, motivational interviewing, and, when indicated, pharmacologic interventions.

Keywords: doping, athletes, steroids, drug abuse, mental illness

\section{Introduction}

Doping, defined as use of drugs or other substances for performance enhancement, has become an important topic in virtually every sport ${ }^{1}$ and has been discovered in athletes of all ages and at every level of competition. ${ }^{2-4}$ See Table 1 for rates of use of a variety of substances, whether doping agents or recreational substances, among different populations of athletes as reported in various recent research studies. ${ }^{5-10}$ Of note, self-reports are generally felt likely to yield under-reported figures. ${ }^{5}$ Importantly, performance-enhancing drugs (PEDs) are not restricted to illegal drugs or prescription medications, such as anabolic steroids. ${ }^{11}$ They include dietary supplements and a variety of compounds that are available at grocery and health food stores and online. ${ }^{12}$

Drug abuse in the athlete population may involve doping in an effort to gain a competitive advantage. Alternatively, it may involve use of substances such as alcohol or marijuana without the intent of performance enhancement, since athletes may develop substance use disorders just as any nonathlete may.

Athletes may turn to substances to cope with numerous stressors, including pressure to perform, injuries, physical pain, and retirement from a life of sport (which happens much earlier than retirement from most other careers). ${ }^{13}$ Additionally, athletes may be significantly less likely to receive treatment for underlying mental illnesses such 
Table I Substance use rates among different populations of athletes as reported in various recent research studies

\begin{tabular}{|c|c|c|}
\hline Substance & Athlete population & Percentage of athletes using substance \\
\hline Any substances banned by WADA & Elite athletes across sports (positive drug tests) & $2 \%$ over past year ${ }^{5}$ \\
\hline Alcohol & College athletes (self report) & $\begin{array}{l}75 \%-93 \% \text { for male athletes; } 71 \%-93 \% \text { for female } \\
\text { athletes over past year }{ }^{6} \\
85 \% \text { over past year }{ }^{7}\end{array}$ \\
\hline \multirow[t]{4}{*}{ Anabolic steroids } & High school students (self report) & $0.7 \%-6.6 \%$ over past year 8 \\
\hline & College athletes (self report) & $\begin{array}{l}0.2 \%-5 \% \text { for males depending on sport; } 0.0 \%-1.6 \% \\
\text { for females depending on sport over past year }{ }^{7,8}\end{array}$ \\
\hline & Professional football players (self report) & $9 \%$ used at some point in career 8 \\
\hline & Competitive power lifters (self report) & $67 \%$ used at some point in career ${ }^{8}$ \\
\hline Cannabis & College athletes (self report) & $28 \%$ over past year ${ }^{7}$ \\
\hline Opiates & Professional football players (self report) & $\begin{array}{l}52 \% \text { used at some point in career ( } 71 \% \text { of those } \\
\text { misused at some point in career) }\end{array}$ \\
\hline \multirow[t]{4}{*}{ Smokeless tobacco } & College athletes (self report) & $23 \%$ over past year ${ }^{7}$ \\
\hline & College baseball players (self report) & $40 \%-50 \%$ over past year ${ }^{10}$ \\
\hline & Professional baseball players (self report) & $35 \%-40 \%$ over past year ${ }^{10}$ \\
\hline & Professional football players (self report) & $20 \%-30 \%$ over past year ${ }^{10}$ \\
\hline Stimulants & College athletes (self report) & $3 \%$ over past year ${ }^{6}$ \\
\hline
\end{tabular}

Abbreviation: WADA, World Anti-Doping Agency.

as depression. ${ }^{14}$ Athletes receive comprehensive treatment and rehabilitation for physical injuries, but this may be less often the case for mental illness, because of their sometimes viewing mental illness as a sign of weakness. ${ }^{14}$ Untreated mental illness is often associated with substance use, perhaps in an effort to self-treat. Alternatively, substances of abuse may cause mental illness. ${ }^{15}$

We will especially focus on doping in this review, which specifically aims to serve as a single paper that provides a broad overview of the history of doping in athletes, the effects of different classes of drugs used for doping, side effects of doping, the role of anti-doping organizations, and the treatment of affected athletes.

\section{Materials and methods}

For this review, we identified studies through a MEDLINE search. Search terms included the following, individually and in combination: "doping", "athletes", "steroids", "drug abuse", "mental illness", "drug testing", "anti-doping", "psychiatry", "sports", "depression", "substance abuse", "substance dependence", "addiction", "history", "side effects", "drug testing", "treatment", "androgens", "testosterone", "growth hormone", "growth factors", "stimulants", "supplements", "erythropoietin", "alcohol", "marijuana", "narcotics", "nicotine", "Beta agonists", "Beta blockers", "diuretics", "masking agents", "gene doping", "National Collegiate Athletic Association", and "World Anti-Doping Agency". We restricted results to the English language and used no date restrictions. We retrieved all papers discussing drug abuse in athletes. We reviewed the findings of each article, and reviewed the references of each paper for additional papers that had been missed in the initial search and that might include findings relevant to the scope of our review. Ultimately, 67 manuscripts or chapters were felt relevant and representative for inclusion among those referenced in this paper.

\section{History of doping in athletes}

The belief that doping is only a recent phenomenon that has arisen solely from increasing financial rewards offered to modern day elite athletes is incorrect. ${ }^{16}$ In fact, doping is older than organized sports. Ancient Greek Olympic athletes dating back to the third century $\mathrm{BC}$ used various brandy and wine concoctions and ate hallucinogenic mushrooms and sesame seeds to enhance performance. Various plants were used to improve speed and endurance, while others were taken to mask pain, allowing injured athletes to continue competing..$^{17-19}$ Yet, even in ancient times, doping was considered unethical. In ancient Greece, for example, identified cheaters were sold into slavery. ${ }^{1}$

The modern era of doping dates to the early 1900s, with the illegal drugging of racehorses. Its use in the Olympics was first reported in 1904. Up until the 1920s, mixtures of strychnine, heroin, cocaine, and caffeine were not uncommonly used by higher level athletes. ${ }^{16}$

By 1930, use of PEDs in the Tour de France was an accepted practice, and when the race changed to national teams that were to be paid by the organizers, the rule book distributed to riders by the organizer reminded them that drugs were not among items with which they would be provided. ${ }^{20}$ 
In the $1950 \mathrm{~s}$, the Soviet Olympic team began experimenting with testosterone supplementation to increase strength and power. ${ }^{16}$ This was part of a governmentsponsored program of performance enhancement by national team trainers and sports medicine doctors without knowledge of the short-term or long-term negative consequences. Additionally, when the Berlin Wall fell, the East German government's program of giving PEDs to young elite athletes was made public. ${ }^{1}$ Many in the sporting world had long questioned the remarkable success of the East German athletes, particularly the females, and their rapid rise to dominance in the Olympics. Young female athletes experienced more performance enhancement than did male athletes. Unfortunately, they also suffered significant and delayed side effects, including reports of early death in three athletes. ${ }^{19}$

The specific substances used to illegally enhance performance have continued to evolve. ${ }^{21}$ The "advances" in doping strategies have been driven, in part, by improved drug testing detection methods. ${ }^{21}$ To avoid detection, various parties have developed ever more complicated doping techniques. ${ }^{21}$ Further, new doping strategies may result from advances in scientific research that can lead to the discovery and use of substances that may later be banned. Over the past 150 years, no sport has had more high-profile doping allegations than cycling. ${ }^{16}$ However, few sports have been without athletes found to be doping.

Many sports organizations have come to ban the use of PEDs and have very strict rules and consequences for people who are caught using them. The International Association of Athletics Federations was the first international governing body of sport to take the situation seriously. ${ }^{22}$ In 1928, they banned participants from doping, ${ }^{22}$ but with little in the way of testing available, they had to rely on the word of athletes that they were not doping. It was not until 1966 that the Federation Internationale de Football Association and Union Cycliste Internationale joined the International Association of Athletics Federations in the fight against drugs, closely followed by the International Olympic Committee (IOC) the following year. ${ }^{23}$

The first actual drug testing of athletes occurred at the 1966 European Championships, and 2 years later the IOC implemented their first drug tests at both the Summer and Winter Olympics. ${ }^{24}$ Anabolic steroids became even more prevalent during the 1970s, and after a method of detection was found, they were added to the IOC's prohibited substances list in 1976. This resulted in a marked increase in the number of doping-related disqualifications in the late
$1970 \mathrm{~s},{ }^{24}$ notably in strength-related sports, such as throwing events and weightlifting.

While the fight against stimulants and steroids was producing results, ${ }^{24}$ the main front in the anti-doping war was rapidly shifting to blood doping. ${ }^{25}$ This removal and subsequent reinfusion of an athlete's blood in order to increase the level of oxygen-carrying hemoglobin has been practiced since the 1970s. ${ }^{25}$ The IOC banned blood doping in $1986 .{ }^{25}$ Other ways of increasing the level of hemoglobin were being tried, however. One of these was erythropoietin..$^{25}$ Erythropoietin was included in the IOC's list of prohibited substances in 1990, but the fight against erythropoietin was long hampered by the lack of a reliable testing method. An erythropoietin detection test was first implemented at the 2000 Olympic Games..$^{25}$

In the $1970 \mathrm{~s}$ and $1980 \mathrm{~s}$, there were suspicions of state-sponsored doping practices in some countries. The former German Democratic Republic substantiated these suspicions. ${ }^{25}$ The most prominent doping case of the 1980s concerned Ben Johnson, the 100 meter dash champion who tested positive for the anabolic steroid stanozolol at the 1988 Olympic Games in Seoul. ${ }^{25}$ In the 1990s, there was a noticeable correlation between more effective test methods and a drop in top results in some sports. ${ }^{25}$

In 1998, police found a large number of prohibited substances, including ampoules of erythropoietin, in a raid during the Tour de France. ${ }^{25,26}$ The scandal led to a major reappraisal of the role of public authorities in anti-doping affairs. As early as 1963, France had been the first country to enact anti-doping legislation. Other countries followed suit, but international cooperation in anti-doping affairs was long restricted to the Council of Europe. In the 1980s, there was a marked increase in cooperation between international sports authorities and various governmental agencies. Before 1998, debate was still taking place in several discrete forums (IOC, sports federations, individual governments), resulting in differing definitions, policies, and sanctions. Athletes who had received doping sanctions were sometimes taking these sanctions, with their lawyers, to civil courts and sometimes were successful in having the sanctions overturned. The Tour de France scandal highlighted the need for an independent, nonjudicial international agency that would set unified standards for anti-doping work and coordinate the efforts of sports organizations and public authorities. The IOC took the initiative and convened the First World Conference on Doping in Sport in Lausanne in February 1999. Following the proposal of the Conference, the World Anti-Doping Agency (WADA) was established later in 1999. 


\section{Performance-enhancing effects of substances used by athletes}

There is a research base demonstrating that many doping agents are in fact performance-enhancing. However, some substances (eg, selective androgen receptor modulators, antiestrogens, and aromatase inhibitors), used in an effort to enhance performance, have little data to back up their effectiveness for such a purpose. Note that the studies cited in this paper are chosen as being historically important or representative of the bulk of the research on the topic, and the broad overview provided in this paper does not aim to cite all evidence on the effects of these substances. Additionally, research on this topic is limited by the difficulty in performing ethical studies due to the high doses of doping agents used, potential side effects, and lack of information on actual practice.

\section{Androgens}

Androgens include exogenous testosterone, synthetic androgens (eg, danazol, nandrolone, stanozolol), androgen precursors (eg, androstenedione, dehydroepiandrosterone), selective androgen receptor modulators, and other forms of androgen stimulation. The latter categories of substances have been used by athletes in an attempt to increase endogenous testosterone in a way that may circumvent the ban enforced on natural or synthetic androgens by WADA.

Amounts of testosterone above those normally found in the human body have been shown to increase muscle strength and mass. For example, a representative randomized, double-blind study involved 43 men being randomized to four different groups: testosterone enanthate $600 \mathrm{mg}$ once per week with strength training exercise; placebo with strength training exercise; testosterone enanthate $600 \mathrm{mg}$ once per week with no exercise; and placebo with no exercise. This was a critical study in demonstrating that administration of testosterone increased muscle strength and fat-free mass in all recipients, and even moreso in those who exercised. ${ }^{27}$ A second study from the same investigators 5 years later further demonstrated a dose-response relationship between testosterone and strength. ${ }^{28}$ Another double-blind trial of exogenous testosterone involved 61 males randomized to five different doses of testosterone enanthate, ranging from $25 \mathrm{mg}$ to $600 \mathrm{mg}$, along with treatment with a gonadotropinreleasing hormone agonist to suppress endogenous testosterone secretion. That study demonstrated findings similar to the previous one, in showing a dose-dependent increase in leg power and leg press strength, which correlated with serum total testosterone concentrations. ${ }^{29}$
Androgen precursors include androstenedione and dehydroepiandrosterone (DHEA). We found no evidence that androstenedione increases muscle strength..$^{30}$ DHEA is available as a nutritional supplement that is widely advertised in body building magazines as a substance that will improve strength. However, results from placebo-controlled studies of DHEA in males have been mixed. ${ }^{30,31}$ One study involved 40 trained males being given DHEA $100 \mathrm{mg}$ per day, androstenedione, or placebo, with no resulting differences in muscle mass or fat-free mass between groups. ${ }^{30}$ A second study involved nine males and ten females randomized to receive DHEA $100 \mathrm{mg}$ daily or placebo for 6 months, who were then crossed over to the other group for a further 6 months. The males but not females showed increased knee and lumbar back strength during DHEA treatment. ${ }^{31}$

Selective androgen receptor modulators are not approved for use in humans in any country, but athletes are able to obtain these substances on the Internet. ${ }^{32}$ No studies were found looking at the effects of selective androgen receptor modulators on muscle strength or mass in humans.

Other forms of androgen stimulation include exogenous human chorionic gonadotropin, antiestrogens such as tamoxifen, clomiphene, and raloxifene, and aromatase inhibitors such as testolactone, letrozole, and anastrozole. These substances may result in increased serum testosterone. ${ }^{33}$ However, we found minimal research demonstrating an effect on muscle strength. ${ }^{34}$ While androgens of different forms have been shown to improve muscle strength and mass, they have not been shown to improve whole body endurance per se. ${ }^{35}$

\section{Growth hormone and growth factors}

Growth hormone and growth factors are also banned by WADA. Research shows recombinant human growth hormone to increase muscle mass and decrease adipose tissue. One representative study randomized male recreational athletes to growth hormone $2 \mathrm{mg}$ /day subcutaneously, testosterone $250 \mathrm{mg}$ weekly intramuscularly, a combination of the two treatments, or placebo. ${ }^{36}$ Female recreational athletes were randomized to growth hormone $2 \mathrm{mg}$ daily or placebo. In both males and females, growth hormone was associated with significantly decreased fat mass, increased lean body mass, and improved sprint capacity (although with no change in strength, power, or endurance). Sprint capacity improvement was even greater when growth hormone and testosterone were coadministered to males.

Growth factors include insulin-like growth factor and insulin. They are presumed to have similar effects to growth hormone, but have not been studied in athletes. ${ }^{37}$ 
Athletes use these substances because of their apparent anabolic effect on muscle. ${ }^{37}$

\section{Stimulants}

Stimulants include amphetamine, D-methamphetamine, methylphenidate, ephedrine, pseudoephedrine, caffeine, dimethylamylamine, cocaine, fenfluramine, pemoline, selegiline, sibutramine, strychnine, and modafinil. Research has shown stimulants to improve endurance, increase anaerobic performance, decrease feelings of fatigue, improve reaction time, increase alertness, and cause weight loss. ${ }^{38}$ Of note, while WADA bans stimulants as a class, it does allow use of caffeine. Energy beverages now often include a variety of stimulants and other additives including not only caffeine, but also the amino acids taurine and L-carnitine, glucuronolactone, ginkgo biloba, ginseng, and others. ${ }^{39}$ Caffeine content can be up to $500 \mathrm{mg}$ per can or bottle. The potential performance benefits of the other ingredients in energy beverages are unclear. For example, taurine may improve exercise capacity by attenuating exercise-induced DNA damage, but the amounts found in popular beverages are probably far below the amounts needed to be of performance-enhancing benefit. $^{39}$

Of note, the number of athletes, especially at top levels of competition, reported to be using stimulant medications has markedly increased in recent years. In the USA, the National Collegiate Athletic Association acknowledged that the number of student athletes testing positive for stimulant medications has increased three-fold in recent years. ${ }^{40}$ There has also been concern about inappropriate use of stimulants in major league baseball in the USA. According to a report released in January 2009, 106 players representing 8\% of major league baseline players obtained therapeutic use exemptions for stimulants in 2008, which was a large increase from 28 players in $2006 .{ }^{41}$ Therapeutic use exemptions allow athletes to take otherwise banned and performance-enhancing substances if their physician attests that they should for medical reasons.

\section{Nutritional supplements}

Nutritional supplements include vitamins, minerals, herbs, extracts, and metabolites. ${ }^{39}$ Importantly, the purity of these substances cannot be guaranteed, such that they may contain banned substances without the athlete or manufacturer being aware. Studies have shown that many nutritional supplements purchased online and in retail stores are contaminated with banned steroids and stimulants. ${ }^{42}$ Thus, athletes could end up failing doping tests without intentionally having ingested banned substances. ${ }^{42}$ Creatine is not currently on the WADA banned list and is the most popular nutritional supplement for performance enhancement. ${ }^{3}$ Studies demonstrate increased maximum power output and lean body mass from creatine. ${ }^{43,44}$ As such, some allowable nutritional supplements may have ergogenic effects, but may have insufficient evidence supporting their ergogenic properties to rise to the level of being banned.

\section{Methods to increase oxygen transport}

Substances athletes use to increase oxygen transport include blood transfusions, erythropoiesis-stimulating agents such as recombinant human erythropoietin and darbepoetin alfa, hypoxia mimetics that stimulate endogenous erythropoietin production such as desferrioxamine and cobalt, and artificial oxygen carriers. Transfusions and erythropoiesis-stimulating agents have been shown to increase aerobic power and physical exercise tolerance. ${ }^{45}$ However, the ergogenic effects of the other agents are debatable. ${ }^{45}$

\section{Other recreational drugs}

Other recreational drugs that may be used in an attempt to enhance performance include alcohol, cannabinoids, narcotics, and nicotine. ${ }^{13}$ WADA does not currently ban nicotine but bans cannabinoids and narcotics. Alcohol is banned in six sports during competition only. All of these substances may be used by athletes to reduce anxiety, which may be a form of performance enhancement, but we found little research looking at actual performance enhancement from these agents. Narcotics are used to decrease pain while practicing or playing. Nicotine may enhance weight loss and improve attention. $^{46}$

\section{Beta agonists}

There is debate as to whether beta-2 adrenergic agonists, for example, albuterol, formoterol, and salmeterol, are ergogenic. ${ }^{47}$ There is anecdotal evidence of improvements in swimmers who use these substances prior to racing. ${ }^{48}$ Additionally, oral beta agonists may increase skeletal muscle, inhibit breakdown of protein, and decrease body fat. ${ }^{48}$ However, there is some evidence suggesting that swimmers may have a relatively high prevalence of airway hyperresponsiveness due to hours spent breathing byproducts of chlorine, such that beta agonists may be needed to restore normal, not enhanced, lung function. ${ }^{49}$

\section{Beta blockers}

Beta blockers such as propranolol result in a decreased heart rate, reduction in hand tremor, and anxiolysis. 
These effects may be performance-enhancing in sports in which it is beneficial to have increased steadiness, such as archery, shooting, and billiards. ${ }^{48}$

\section{Other prescription drugs}

Diuretics and other masking agents may be used as doping agents. ${ }^{12}$ Diuretics can result in rapid weight loss such that they may be used for a performance advantage in sports with weight classes, such as wrestling and boxing. ${ }^{12}$ Diuretics may also be used to hasten urinary excretion of other PEDs, thereby decreasing the chances that athletes will test positive for other banned substances that they may be using. ${ }^{12}$ Masking agents in general conceal prohibited substances in urine or other body samples, and include diuretics, epitestosterone (to normalize urine testosterone to epitestosterone ratios), probenecid, 5-alpha reductase inhibitors, and plasma expanders (eg, glycerol, intravenous administration of albumin, dextra, and mannitol). ${ }^{50}$

Glucocorticoids are sometimes used by athletes in an attempt to enhance performance because of their antiinflammatory and analgesic properties. ${ }^{12}$ However, there is minimal research to show any performance benefits of this class of drugs.

Athletes may also use phosphodiesterase-5 inhibitors in an attempt to attain increased oxygenation and exercise capacity, since they have vasodilatory effects. ${ }^{51}$ However, again, little research exists to support a performance benefit from these substances.

Psychiatric medications, including antidepressants, anxiolytics, antipsychotics, and anticonvulsants, are generally not on the WADA banned list. ${ }^{14}$ Bupropion is an antidepressant that is on the WADA 2014 monitoring list, meaning WADA is monitoring for any concerning trends of inappropriate use. One small study of nine males suggested that bupropion, when used acutely in warm environments, may allow athletes to push themselves to higher body temperature and heart rates without perceiving greater effort. ${ }^{52}$ Otherwise, there is very minimal evidence that any of these classes of psychiatric medications enhance performance. ${ }^{14}$

\section{Nondrug performance- enhancing measures}

Gene doping is a concerning potential method of nondrug performance enhancement and is banned by WADA. The potential to directly affect strength and endurance through gene manipulation has been demonstrated in laboratory mice, but no human athletes thus far have been found to be using this method. ${ }^{16}$
Additionally, athletes may legally attempt to improve physical performance in a number of nondrug ways. ${ }^{53}$ These have varying degrees of research into their effectiveness and safety, and include hypoxia induction techniques. ${ }^{53}$ For example, athletes may train at high altitudes, which can result in erythrocytosis. Some studies suggest that a highlow method of sleeping at high altitude followed by training at low altitude is a better training strategy than training or sleeping at either high or low altitudes alone. ${ }^{54}$ Some athletes have tried sleeping at simulated high altitude by using low oxygen tents. Athletes may also make dietary changes to try to increase hemoglobin levels. ${ }^{55,56}$

\section{Side effects of substances used by athletes}

It is presumed that most if not all doping agents have potential short-term and/or long-term side effects. Unfortunately, given the high doses of these agents used by athletes, it is difficult to confirm such effects. It would be unethical to give dosages as high as those used by athletes for performance enhancement effects to participants in research studies. ${ }^{16}$ Knowledge about side effects may be gleaned from empirical observation, reports of admitted users, and effects in patients prescribed such agents for medical conditions. Table 2 lists the potential side effects of various forms of doping. ${ }^{57-59}$

\section{Anti-doping organizations, drug testing in athletes, and rules}

Drug testing typically occurs only in organized, competitive sports. At the college level, organizations such as the National Collegiate Athletic Association ${ }^{60}$ and individual member institutions conduct standard drug testing programs and enforce penalties for positive tests.

Elite athletes competing at international and national levels are subject to standardized anti-doping guidelines under the auspices of WADA and related national organizations. WADA is the international independent agency that publishes the World Anti-Doping Code, which is the document harmonizing anti-doping policies in all sports and all countries. ${ }^{61}$ The Code was first adopted in 2003 and became effective in 2004. The Code sets forth specific anti-doping rules and principles that are to be followed by the anti-doping organizations responsible for adopting, implementing, or enforcing anti-doping rules within their authority, including the IOC, International Paralympic Committee, international sport federations (for example, the International Cycling Union), major event organizations, and national anti-doping organizations (for example, the US Anti-Doping Agency). 
Table 2 Potential side effects of different substances and methods of doping

Substance/method
Androgens (eg, testosterone, danazol, nandrolone,
stanozolol)

Growth hormone and growth factors (eg, insulin-like growth factor, insulin)

Stimulants (eg, amphetamine, D-methamphetamine, methylphenidate, ephedrine, pseudoephedrine, caffeine, cocaine)

Methods to increase oxygen transport (eg, blood transfusions, recombinant human erythropoietin, darbepoetin alfa) Nutritional supplements (eg, vitamins, minerals, herbs, extracts, metabolites)

Other recreational drugs

Beta agonists (eg, albuterol, formoterol, salmeterol))

Beta blockers (eg, propranolol)

Other prescription drugs

\section{Potential side effects}

- Reproductive: diminished spermatogenesis and gynecomastia in men, decreased fertility, decreased testicular size, possible benign prostatic hypertrophy or prostate cancer

- Cardiovascular: decreased high-density lipoprotein cholesterol, increased low-density lipoprotein cholesterol

- Hepatic: hepatotoxicity

- Neuropsychiatric: depression, mania, psychosis, aggression

- Other: hastened epiphyseal closure in adolescents, acne, hirsutism, temporal hair recession, clitoromegaly, voice deepening, and oligomenorrhea/amenorrhea in women, infections (abscesses at injection sites, septic arthritis, and hepatitis/human immunodeficiency virus from sharing needles), tendon rupture

- Insulin resistance, hyperglycemia, diabetes mellitus, cardiomegaly, hastened epiphyseal closure in adolescents, myopathy, hypertension, edema, carpal tunnel syndrome

- Hypertension, tachycardia, myocardial infarction, stroke, heat stroke, weight loss, rhabdomyolysis, headache, nausea, tremor, insomnia, anxiety/panic attacks, agitation, aggression, psychosis

- Myocardial infarction, stroke, deep vein thrombosis/pulmonary embolism, hypertension, antibody-mediated anemia

- Depends on the components

- Creatine: acute interstitial nephritis, more rapid progression of chronic kidney disease ${ }^{57,58}$

- Alcohol: sedation, decreased concentration and coordination

- Cannabinoids: reduced alertness, impaired short-term memory, psychomotor retardation, dysphoria, anxiety, psychosis ${ }^{59}$

- Narcotics: physical dependence, nausea/vomiting, constipation, decreased concentration and coordination, fatigue

- Nicotine: chronic use associated with cardiovascular disease, chronic obstructive lung disease, and many types of cancer

- Tachycardia, arrhythmias, hypokalemia, hyperglycemia, tremor

- Bradycardia, increased airway resistance, decreased endurance

- Diuretics and other masking agents: dizziness, muscle cramps, rash, gout, renal insufficiency, electrolyte imbalances, gynecomastia (spironolactone)

- Glucocorticoids: hyperglycemia, fluid retention, depression, mania, psychosis, chronic use may result in reduced muscle mass/weakness, osteoporosis, diabetes mellitus, hypertension, weight gain, central obesity, and cataracts

- Unknown

Gene doping

Note: Copyright (C) 2013. John Wiley \& Sons. Adapted with permission from Baron DA, Reardon CL, Baron SH. Doping in sport. In: Baron DA, Reardon CL, Baron SH, editors. Clinical Sports Psychiatry: An International Perspective. Oxford, UK: Wiley; 2013. ${ }^{16}$

WADA revises and publishes its list of banned substances approximately annually. It specifies those banned substances and methods that are prohibited at all times (both in-competition and out-of-competition) because of their potential to enhance performance in future competitions or their masking potential, and those substances and methods that are prohibited in-competition only. The list may be expanded by WADA for a particular sport.

WADA has also taken the lead in the development of the athlete biological passport concept. ${ }^{61}$ WADA's athlete biological passport operating guidelines took effect in 2009. The fundamental principle of the athlete biological passport is based on the monitoring of selected parameters over time that indirectly reveal the effect of doping, as opposed to the traditional direct detection of doping by analytical means. This concept gained momentum as a result of questions raised during the 2006 Olympic Winter Games surrounding suspensions of athletes by their federations following health checks that reported high hemoglobin levels. An athlete's passport purports to establish individual baseline hormone/blood levels, which are monitored over time for significant changes. A positive test result would consist of too dramatic a change from the established individual baseline. This approach is intended to protect athletes from false-positive tests resulting from naturally occurring high levels of endogenous substances, while catching those attempting to cheat by using naturally occurring substances.

In the event that an athlete and his or her medical providers feel it necessary, for documented medical reasons, that he or she continue to take a banned substance, WADA may consider granting a therapeutic use exemption, a concept 
mentioned earlier. A therapeutic use exemption must be on file before an athlete tests positive for the substance allowed by that therapeutic use exemption.

\section{Treatment of affected athletes, including counseling and psychiatric support}

The first level of addressing the problem of drug abuse by athletes is prevention. ${ }^{13}$ Drug screening is used in higherlevel athletics both to deter athletes from using drugs and to punish and offer opportunities for rehabilitation to those who are found to have done so. Didactic education is another method aimed at prevention. ${ }^{62}$ On the one hand, some authors and clinicians feel that among the most effective preventive strategies for drug abuse in sports is frequent, accurate, very closely observed, truly random urine drug testing. ${ }^{13,63}$ However, some view drug testing as ineffective at preventing use of PEDs. ${ }^{64}$ The argument for the latter is that these interventions target doping behavior rather than athlete attitudes. Athletes ultimately focus on their performance, and thus may view doping as rational behavior. ${ }^{63}$ Moreover, knowledge of the potentially dangerous consequences from doping imparted via didactic education does not necessarily dissuade athletes. For example, in 1997, Bamberger and Yaeger surveyed 198 Olympic athletes. When asked if they would use PEDs under the hypothetical conditions of knowing they would not be caught and knowing their use would result in victory, 195 of 198 responded "yes". Moreover, if the caveat was added that they would die within 5 years, $61 \%$ of the athletes still said they would use them. ${ }^{65}$

There is little research available to guide counseling and psychiatric approaches to treatment of athletes who abuse drugs. ${ }^{64}$ However, motivational interviewing approaches have been suggested for athletes with drug abuse or doping problems, since athletes may often present in the precontemplation stage of change. ${ }^{13,64}$ Important elements of motivational interviewing include: ${ }^{64}$

1. Clinician empathy

2. Developing discrepancies between where the athlete wants to go in life after sport and the impact that continued use of the substance might have on those goals. During this process, the provider helps athletes to clarify conflict among their values, motives, interest, and behaviors.

3. Rolling with resistance. When resistance inevitably occurs, providers should avoid arguing with athletes, as that can exacerbate resistance to change. The provider may "agree to disagree" on certain points with some athletes. Providers may propose or "wonder about"
Table 3 Common signs and symptoms of substances relatively commonly used by athletes

\begin{tabular}{|c|c|}
\hline Substance & Common signs and symptoms of use \\
\hline Alcohol & $\begin{array}{l}\text { Sedation, decreased concentration and coordination, } \\
\text { disinhibition, slurred speech, vomiting }\end{array}$ \\
\hline $\begin{array}{l}\text { Anabolic } \\
\text { steroids }\end{array}$ & $\begin{array}{l}\text { Acne, rapid muscle gain, irritability, gynecomastia } \\
\text { and hair loss in males, deepening of voice and facial } \\
\text { hair in females, visible injection sites and cysts }\end{array}$ \\
\hline Cannabinoids & $\begin{array}{l}\text { Bloodshot eyes, increased appetite, slowed } \\
\text { responses, cough, lack of motivation, paranoia }\end{array}$ \\
\hline Opiates & $\begin{array}{l}\text { Constricted pupils, sedation, slowed responses, } \\
\text { slurred speech, constipation }\end{array}$ \\
\hline Stimulants & $\begin{array}{l}\text { Dilated pupils, anxiety, jitteriness, increased heart } \\
\text { rate and blood pressure, loss of appetite, tics }\end{array}$ \\
\hline
\end{tabular}

Note: Copyright $\odot$ 2013. John Wiley \& Sons. Adapted with permission from Morse ED. Substance use in athletes. In: Baron DA, Reardon CL, Baron SH, editors. Clinical Sports Psychiatry: An International Perspective. Oxford, UK: Wiley; 2013., 8,13

certain alternative viewpoints or actions, but they do not impose or insist upon them.

4. Encouragement of self-efficacy. Athletes may need to shift their viewpoint from one of being willing to do whatever it takes to win, to acknowledging that they would use PEDs only if ultimately incapable of succeeding without them (with the hope that athletes will never get to that point).

If an athlete is physically dependent on a drug, then additional strategies may be needed. These may include pharmacologic interventions such as naltrexone, acamprosate, or disulfiram for alcohol dependence, or buprenorphine for opiate dependence. ${ }^{13}$ Additionally, providers should assess for comorbid mental illness, since co-occurrence of physical dependence and mental illness is commonplace. ${ }^{13}$ Any underlying mental illness should be treated. ${ }^{13}$ A recent review paper on the epidemiology of mental illness in athletes noted that some mental illnesses such as depression are probably as common in athletes as nonathletes. ${ }^{14}$ Twelve-step facilitation, cognitive behavioral therapy, and network therapy are also approaches that may be helpful for athletes who are abusing drugs, although studies are preliminary. ${ }^{10,13,66}$

\section{Conclusion and suggestions}

Drug abuse in athletes is a significant problem that has many potential underlying causes. The drive to be the best in sport dates to ancient times, as does the use of performanceenhancing substances. With the ever-mounting pressures faced by athletes, it is not surprising that drug abuse by athletes exists across essentially all sports and age groups.

Suggestions for those undertaking research and clinical work with athletes include:

1. If providers become aware of an athlete using PEDs, they should educate the athlete about the potential 
risks of continued use, regardless of any evidence that suggests this may not be influential for all athletes. Providers should encourage discontinuation of the abused substance(s).

2. There is great variance in drug testing programs in different sports and at different levels of competition. ${ }^{13}$ More highquality, prospective, randomized trials should be undertaken to determine the deterrent efficacy of various types of PED screening programs, and changes should be made to those types of screening programs found to be ineffective. ${ }^{8}$

3. Physicians, trainers, coaches, parents, and others in the athlete entourage need to be well trained in recognizing the signs and symptoms of drug abuse, including changes in physical health and behaviors (Table 3).

4. The efficacy of education about PED use as a preventative measure needs further study. Early integration of well designed prevention curricula into sports programs may be beneficial. ${ }^{8}$ However, as alluded to earlier, at least one preliminary study suggests that educational programs that solely emphasize the negative effects of PEDs may be ineffective for young athletes. ${ }^{67}$

5. Mental health professionals should be included in the network of team doctors and other health care providers readily available to athletes. Psychiatrists are often helpful in developing strong drug prevention policies that emphasize education and treatment and not just sanctions. ${ }^{13}$ Mental health care professionals should have a year-round presence with the athletes and teams with whom they are working so as to build trust. ${ }^{13}$

6. Screening for and treatment of underlying mental illnesses such as depression that may contribute to selftreatment with drugs by athletes should be increased. The effectiveness of this screening should be studied.

7. Athletes who are using drugs are often skeptical of the medical field. This may be partly with good reason, as many health care professionals are unfamiliar with the mentality of athletes or common drug abuse patterns in this population. Accordingly, referral networks or team assistance programs consisting of health care professionals familiar with these issues should be established for athletes and teams. ${ }^{62}$ The effectiveness of these models should be studied.

8. Research should examine differences in treatment approaches that may be needed for athletes who have been using drugs for a shorter versus longer period of time.

Trainers, coaches, and health care providers should provide evidence-based, safe alternatives to PED use, including optimal nutrition, weight-training strategies, and psychological approaches to improving performance, all of which may help with athletes' confidence in their natural abilities.

\section{Disclosure}

The authors report no conflicts of interest in this work.

\section{References}

1. Baron DA, Martin DM, Abol Magd S. Doping in sports and its spread to at-risk populations: an international review. World Psychiatry. 2007;6:118-123.

2. Catlin DH, Murray TH. Performance-enhancing drugs, fair competition, and Olympic sport. JAMA. 1996;276:231-237.

3. Fernandez MM, Hosey RG. Performance-enhancing drugs snare nonathletes, too. J Fam Pract. 2009;58:16-23.

4. Metzl JD, Small E, Levine SR, Gershel JC. Creatine use among young athletes. Pediatrics. 2001;108:421-425.

5. Uvacsek M, Nepusz T, Naughton DP, Mazanov J, Ranky MZ, Petroczi A Self-admitted behavior and perceived use of performance-enhancing vs psychoactive drugs among competitive athletes. Scand J Med Sci Sports. 2011;21:224-234.

6. National Institute on Drug Abuse, US Department of Health and Human Services. Monitoring the future national survey on drug use, 1975-2003, volume II. College students and adults ages 19-25. Available from: http://www.monitoringthefuture.org/pubs/monographs/vol2_2003.pdf. Accessed June 12, 2014.

7. Green GA, Uryasz FD, Petr TA, et al. NCAA study of substance abuse habits of college student-athletes. Clin J Sports Med. 2001;11:51-56.

8. Kersey RD, Elliot DL, Goldberg L, et al. National Athletic Trainers' Association position statement: anabolic-androgenic steroids. $J$ Athl Train. 2012;47:567-588.

9. CottlerLB,AbdallahAB, Cummings SM, Barr J, Banks R, Forchheimer R. Injury, pain, and prescription opioid use among former National Football League (NFL) players. Drug Alcohol Depend. 2011;116: 188-194.

10. McDuff DR, Baron D. Substance use in athletics: a sports psychiatry perspective. Clin Sports Med. 2005;24:885-897.

11. Wanjek B, Rosendahl J, Strauss B, Gabriel HH. Doping, drugs and drug abuse among adolescents in the State of Thuringia (Germany): prevalence, knowledge and attitudes. Int J Sports Med. 2007;28:346-353.

12. Botre F, Pavan A. Enhancement drugs and the athlete. Phys Med Rehabil Clin N Am. 2009;20:133-148.

13. Morse ED. Substance use in athletes. In: Baron DA, Reardon CL, Baron SH, editors. Clinical Sports Psychiatry: An International Perspective. Oxford, UK: Wiley; 2013.

14. Reardon CL, Factor RM. A systematic review of diagnosis and medical treatment of mental illness in athletes. Sports Med. 2010;40:961-980.

15. Riggs P, Levin F, Green AI, et al. Comorbid psychiatric and substance abuse disorders: recent treatment research. Subst Abuse. 2008; 29:51-63.

16. Baron DA, Reardon CL, Baron SH. Doping in sport. In: Baron DA, Reardon CL, Baron SH, editors. Clinical Sports Psychiatry: An International Perspective. Oxford, UK: Wiley; 2013.

17. Yesalis CE. History of doping in sport. In: Bahrke MS, Yesalis CE, editors. Performance Enhancing Substances in Sport and Exercise. Champaign, IL, USA: Human Kinetics; 2002.

18. Landry GL, Kokotailo PK. Drug screening in athletic settings. Curr Problems Pediatr. 2004;24:344-359.

19. Franke WW, Berendonk B. Hormonal doping and androgenization of athletes: a secret program of the German Democratic Republic. Clin Chem. 1997;43:1262-1279.

20. McGann B, McGann C. The Story of the Tour de France. Indianapolis, IN, USA: Dog Ear Publishing; 2006. 
21. Teale P, Scarth J, Judson S. Impact of the emergence of designer drugs upon sports doping testing. Bioanalysis. 2012;4:71-88.

22. International Association of Athletics Federations. IAAF commitment to healthy and drug free athletic, 2013. Available from: http:// www.iaaf.org/about-iaaf/medical-anti-doping. Accessed August 29, 2013.

23. Federation Internationale de Football Association. A brief history of doping, 2013. Available from: http://www.fifa.com/aboutfifa/ footballdevelopment $/$ medical $/$ news $/$ newsid=514062 $/$ index.html. Accessed August 29, 2013.

24. International Olympic Committee. Factsheet: the fight against doping and promotion of athletes' health, 2013. Available from: http:// www.olympic.org/Documents/Reference_documents_Factsheets/ Fight_against_doping.pdf. Accessed August 29, 2013.

25. World Anti-Doping Agency. A brief history of anti-doping, 2010. Available from: http://www.wada-ama.org/en/about-wada/history/. Accessed August 29, 2013.

26. Voet W. Breaking the Chain. London, UK: Random House; 1999

27. Bhasin S, Storer TW, Berman N, et al. The effects of supraphysiologic doses of testosterone on muscle size and strength in normal men. N Engl J Med. 1996;335:1-7.

28. Bhasin S, Woodhouse L, Casaburi R, et al. Testosterone dose-response relationships in healthy young men. Am J Physiol Endocrinol Metab. 2001;281:E1172-E1181.

29. Storer TW, Magliano L, Woodhouse L, et al. Testosterone dosedependently increases maximal voluntary strength and leg power, but does not affect fatigability or specific tension. J Clin Endocrinol Metab. 2003;88:1478-1485.

30. Wallace MB, Lim J, Cutler A, Bucci L. Effects of dehydroepiandrosterone vs androstenedione supplementation in men. Med Sci Sports Exerc. 1999;31:1788-1792.

31. Morales AJ, Haubrich RH, Hwang JY, Asakura H, Yen SS. The effect of six months treatment with a $100 \mathrm{mg}$ daily dose of dehydroepiandrosterone (DHEA) on circulating sex steroids, body composition and muscle strength in age-advanced men and women. Clin Endocrinol. 1998;49:421-432.

32. Kohler M, Thomas A, Geyer H, Petrou M, Schanzer W, Thevis M. Confiscated black market products and nutritional supplements with non-approved ingredients analyzed in the Cologne Doping Control Laboratory 2009. Drug Test Anal. 2010;2:533-537.

33. Handelsman DJ. Clinical review: the rationale for banning human chorionic gonadotropin and estrogen blockers in sport. J Clin Endocrinol Metab. 2006;91:1646-1653.

34. Handelsman DJ. Indirect androgen doping by oestrogen blockage in sports. Br J Pharmacol. 2008;154:598-605.

35. Basaria S. Androgen abuse in athletes: detection and consequences. J Clin Endocrinol Metab. 2010;95:1533-1543.

36. Meinhardt U, Nelson AE, Hansen JL, et al. The effects of growth hormone on body composition and physical performance in recreational athletes: a randomized trial. Ann Intern Med. 2010;152:568-577.

37. Holt RI, Sonksen PH. Growth hormone, IGF-I and insulin and their abuse in sport. Br J Pharmacol. 2008;154:542-556.

38. Eichner ER. Stimulants in sports. Curr Sports Med Rep. 2008;7: 244-245.

39. Higgins P, Tuttle TD, Higgins CL. Energy beverages: content and safety. Mayo Clin Proc. 2010;85:1033-1041.

40. National College Athletic Association. NCAA guidelines to document ADHD treatment with banned stimulant medications. Addendum to the Jan 2009 guideline, 2010. Available from: http://www.lagrange. edu/resources/pdf/athletics/athletictraining/FAQ.pdf. Accessed June 12, 2014.

41. Shaikin B. Los Angeles Times. Baseball's 2008 drug test results released in report. January 10, 2009 Available from: http:// articles.latimes.com/2009/jan/10/sports/sp-newswire10. Accessed September 17, 2010.
42. Judkins C, Prock P. Supplements and inadvertent doping - how big is the risk to athletes. Med Sports Sci. 2012;59:143-152.

43. Kendall KL, Smith AE, Graef JL, et al. Effects of four weeks of high-intensity interval training and creatine supplementation on critical power and anaerobic working capacity in college-aged men. J Strength Cond Res. 2009;23:1663-1669.

44. Branch JD. Effect of creatine supplementation on body composition and performance: a meta-analysis. Int J Sport Nutr Exerc Metab. 2003;13: 198-226.

45. Elliott S. Erythropoiesis-stimulating agents and other methods to enhance oxygen transport. Br J Pharmacol. 2008;154:529-541.

46. Bailey JA, Averbuch RN, Gold MS. Cosmetic psychiatry: from Viagra to MPH. Directions in Psychiatry. 2009;29:1-13.

47. Kindermann W. Do inhaled beta(2)-agonists have an ergogenic potential in non-asthmatic competitive athletes? Sports Med. 2007;37:95-102.

48. Davis E, Loiacono R, Summers RJ. The rush to adrenaline: drugs in sport acting on the beta-adrenergic system. Br J Pharmacol. 2008;154: 584-597.

49. Bougault V, Boulet LP. Is there a potential link between indoor chlorinated pool environment and airway remodeling/inflammation in swimmers? Expert Rev Respir Med. 2012;6:469-471.

50. World Anti-Doping Agency. The World Anti-Doping Code: The 2013 Prohibited List International Standard, 2013. Available from: http://www.wada-ama.org/Documents/World_Anti-Doping_Program/ WADP-Prohibited-list/2013/WADA-Prohibited-List-2013-EN.pdf. Accessed August 23, 2013.

51. Petroczi A, Naughton DP. Potentially fatal new trend in performance enhancement: a cautionary note on nitrate. J Int Soc Sports Nutr. 2010;7:25.

52. Watson P, Hasegawa H, Roelands B, Piacentini MF, Looverie R, Meeusen R. Acute dopamine/noradrenaline reuptake inhibition enhances human exercise performance in warm, but not temperate conditions. J Physiol. 2005;565 Pt 3:873-883.

53. Schmitt L, Millet G, Robach P, et al. Influence of "living high-training low" on aerobic performance and economy of work in elite athletes. Eur J Appl Physiol. 2006;97:627-636.

54. Vardy J, Judge K. Can knowledge protect against acute mountain sickness? J Public Health. 2005;27:366-370.

55. Suedekum NA, Dieff R. Iron and the athlete. Curr Sports Med Rep. 2005;4:199-202.

56. Maughan RJ, Shirreffs SM. Nutrition for sports performance: issues and opportunities. Proc Nutr Soc. 2012;71:112-119.

57. Koshy KM, Griswold E, Schneeberger EE. Interstitial nephritis in a patient taking creatine. $N$ Engl J Med. 1999;340:814-815.

58. Edmunds JW, Jayapalan S, DiMarco NM, Saboorian MH, Aukema HM. Creatine supplementation increases renal disease progression in Han:SPRD-cy rats. Am J Kidney Dis. 2001;37:73-78.

59. Saugy M, Avois L, Saudan C, et al. Cannabis and sport. Br J Sports Med. 2006;40 Suppl 1:i13-i15.

60. National Collegiate Athletic Association. Drug testing, 2012. Available from: http://www.ncaa.org/wps/wcm/connect/public/NCAA/ Health+and+Safety/Drug+Testing/Drug+Testing+Landing+Page . Accessed April 20, 2013.

61. World Anti-Doping Agency, 2013. Available from: http://www.wadaama.org/en. Accessed April 18, 2013.

62. Morse ED. Sports psychiatrists working in college athletic departments. In: Baron DA, Reardon CL, Baron SH, editors. Clinical Sports Psychiatry: An International Perspective. Chichester, UK: Wiley; 2013.

63. Harcourt PR, Unglik H, Cook JL. A strategy to reduce illicit drug use is effective in elite Australian football. Br J Sports Med. 2012;46: 943-945.

64. Johnson MB, Sacks DN, Edmonds WA. Counseling athletes who use performance-enhancing drugs: a new conceptual framework linked to clinical practice. J Soc Behav Health Sci. 2010;4:1-29. 
65. Bamberger M, Yaeger D. Over the edge. Sports Illustrated. April 14, 1997. Available from; http://sportsillustrated.cnn.com/vault/article/ magazine/MAG1009868/index.htm. Accessed June 17, 2014.

66. Corcoran JP, Longo ED. Psychological treatment of anabolic-androgenic steroid-dependent individuals. J Subst Abuse Treat. 1992;9:229-235.
67. Goldberg L, Bents R, Bosworth E, Trevisan L, Elliot DL. Anabolic steroid education and adolescents: do scare tactics work? Pediatrics. 1991;87:283-286.

Substance Abuse and Rehabilitation

\section{Publish your work in this journal}

Substance Abuse and Rehabilitation is an international, peer-reviewed, open access journal publishing original research, case reports, editorials, reviews and commentaries on all areas of addiction and substance abuse and options for treatment and rehabilitation. The manuscript management system is completely online and includes a very quick and fair peer-review system. Visit http://www.dovepress.com/testimonials.php to read real quotes from published authors. 